\title{
Acknowledgment of Priority
}

WHEN DOES A RANDOMLY WEIGHTED SELF-

\section{NORMALIZED SUM CONVERGE IN DISTRIBUTION?}

\author{
(Elect. Comm. in Probab. 10 (2005), 70-81) \\ DAVID M. MASON ${ }^{1}$ \\ Statistics Program, University of Delaware, Newark, DE 19717 \\ email: davidm@udel.edu \\ JOEL ZINN ${ }^{2}$ \\ Department of Mathematics, Texas A $6 M$ University, College Station, TX 77843-3368 \\ email: email.com jzinn@math.tamu.edu
}

Submitted: December 24, 2005 Accepted in Final Form: December 29, 2005

AMS 2000 Subject classification: 60F05

Keywords: Domain of attraction, self-normalized sums, regular variation

Christian Houdré has kindly pointed us to a paper by A. Fuks, A. Joffe and J. Teugels, where their Theorem 5.3 is our Proposition 3 in the case $0<\alpha<1$.

\section{References}

[1] D. M. Mason and J. Zinn, When does a randomly weighted self-normalized sum converge in distribution? Elec. Comm. Probab. 10 (2005), 70-81

[2] A. Fuks, A. Joffe and J. Teugels, Expectation of the ratio of the sum of squares to the square of the sum: exact and asymptotic results. (Russian) Teor. Veroyatnost. i Primenen. (2001) 46, no. 2, 297-310; translation in Theory Probab. Appl. (2002) 46, no. 2, 243-255.

\footnotetext{
${ }^{1}$ RESEARCH PARTIALLY SUPPORTED BY NSA GRANT MDA904-02-1-0034 AND NSF GRANT DMS-0203865

${ }^{2}$ RESEARCH PARTIALLY SUPPORTED BY NSA GRANT H98230-04-1-0108
} 